\title{
O FLUXO DE INFORMAÇÃO SOB A ÓTICA DE GESTORES PÚBLICOS EM TURISMO
}

\section{EL FLUJO DE LA INFORMACIÓN EN LA PERSPECTIVA DE LOS GESTORES PÚBLICOS EN EL SECTOR TURÍSTICO}

\author{
Luciane Paula Vital - lucianepvital@gmail.com \\ Doutoranda em Ciência da Informação pela Universidade Federal de \\ Santa Catarina (UFSC). Professora da UFSC. \\ Vivian Mengarda Floriani - vivifloriani@hotmail.com \\ Mestre em Ciência da Informação pela Universidade Federal de Santa \\ Catarina (UFSC). \\ Gregório Varvakis - grego@deps.ufsc.br \\ Doutor em Manufacturing Engineering pela Loughborough University of \\ Technology (LBORO), Inglaterra. Professor da Universidade Federal de \\ Santa Catarina (UFSC).
}

\section{RESUMO}

Introdução: A informação desempenha papel importante e imprescindível em todas as organizações públicas e privadas, exigindo gerenciamento eficaz e esforços conjuntos dos seus membros. A gestão da informação requer o estabelecimento de processos, etapas ou fluxos sistematizados e estruturados, associado às pessoas responsáveis por sua condução, para que se obtenham os resultados almejados. O turismo é uma atividade socioeconômica que tem despertado a atenção de governos, empresários, comunidades e estudiosos, principalmente quanto à sua organização e gestão.

Objetivo: O objetivo deste estudo foi analisar o fluxo informacional subsidiando o processo de tomada de decisões em um órgão municipal de turismo.

Metodologia: A pesquisa caracteriza-se como quanti-qualitativa, estudo de caso e a de técnica de coleta de dados foi a entrevista semi-estruturada, aplicada com os três gestores responsáveis pela Secretaria.

Resultados: Os resultados confirmaram que, embora o fluxo tenha alguma estrutura, não é dotado de sistematização formal, ocorrendo deficiências nas suas etapas. 
Conclusão: A investigação sobre o fluxo informacional reflete um caminho para a consolidação da atividade turística e o reconhecimento da sua importância enquanto fenômeno socioeconômico e cultural. Em vista dos resultados obtidos, deduz-se que a centralização, associada à subutilização do fluxo informacional compromete a qualidade do processo de tomada de decisões.

Palavras-chave: Fluxo de informação. Tomada de decisão. Turismo.

\section{INTRODUÇÃO}

O turismo, inserido no setor de prestação de serviços, é uma respeitada atividade socioeconômica que tem despertado a atenção de governos, empresários, comunidades e estudiosos, principalmente quanto a sua organização e gestão. Segundo dados da Organização Mundial do Turismo - OMT (2001), a indústria turística fechou o ano de 2010 com 935 milhões de turistas, 6,7\% a mais que o ano anterior, e com previsão de crescimento entre 4\% e 5\% em 2011.

Por sua complexidade, a atividade é carente de estudos que possibilitem compreendê-la e avaliá-la. A análise do processo, das atividades e dos resultados em turismo demanda um conhecimento abrangente e conexo a uma maturidade da comunidade local, governo, turistas e iniciativa privada. Especificamente no âmbito do poder público, tal maturidade é ainda mais evidenciada, pois as destinações turísticas (localidade, município, região ou país) exigem um gerenciamento eficaz de seus recursos.

Nesse sentido, o estudo da gestão e dos fluxos de informação pode se constituir em importante aporte para a administração da atividade turística, principalmente como subsídio ao processo de tomada de decisões, devido à incipiência e carência da área.

O presente estudo investigou o fluxo da informação em um organismo municipal de turismo, com foco nos gestores, analisando-o em três etapas: o fluxo coletado do ambiente externo, o produzido no ambiente interno e o produzido para o mercado externo. Buscando, assim, mapear o fluxo informacional da Secretaria, objetivando aprimorá-lo para uma tomada de decisão mais consistente.

O ambiente do estudo compreendeu uma Secretaria Municipal de Turismo (SECTUR), focado nos seus gestores. O local onde está inserida a organização é 
um importante pólo receptor de turistas, cuja tipologia está voltada ao turismo de sol e praia.

A pesquisa caracteriza-se como quanti-qualitativa, estudo de caso e a de técnica de coleta de dados foi a entrevista semi-estruturada, aplicada com os três gestores responsáveis pela Secretaria. O roteiro da entrevista contou com 32 (trinta e duas) questões norteadoras. A discussão recaiu sobre os canais e fontes de informação, os atores e sua atuação, as necessidades e as barreiras informacionais dos atores, a análise do fluxo informacional, o processo decisório e as sugestões que possam contribuir para a organização.

\section{ANÁLISE DOS RESULTADOS}

Os três gestores são do sexo masculino, com idade concentrada na faixa etária dos 50 anos. O grau de escolaridade do Secretário Municipal é graduação completa; do diretor 1 é pós-graduação completa em nível de especialização e incompleta em nível de mestrado; e a do diretor 2 é graduação incompleta.

A formação acadêmica do Secretário é turismo e hotelaria, a do diretor 1 é administração e especialização em turismo e a do diretor 2 não foi possível obter. Observa-se que a formação dos gestores é específica na área em que atuam, representando um aspecto positivo para a administração do órgão. É importante considerar ainda que a formação acadêmica com base no turismo pode auxiliar na busca de canais e fontes de informação, uma vez que os conhecem.

Para efeito de análise, são adotados os termos 'secretário' para denominar o gestor principal da organização, 'diretor 1' para o cargo de Diretor do Setor de Planejamento e Pesquisa (SEPLAN) e 'diretor 2' para o cargo de Diretor do setor de marketing e eventos.

A forma de ingresso na Secretaria foi através do cargo de confiança concedido por autoridades do poder público municipal. Em relação ao tempo de trabalho junto a SECTUR, verifica-se que o secretário está há 10 (dez) anos na organização, seguido do diretor 2 com 7 (sete) anos e finalmente o diretor 1 com 2 (dois) anos de trabalho no órgão. A condução da administração pública do município pesquisado está a cargo de um único partido político há cerca de 10 (dez) anos. Em vista disso, a administração pública consegue dar seqüência aos planos previstos 
em longo prazo, evitando a interrupção das atividades no final de um mandato. Por outro lado, um longo período de administração pelos mesmos gestores pode fazer com que a gestão do órgão fique viciada em padrões gerenciais, comprometendo a eficácia do processo e a renovação de planos de ação.

O tempo em que os gestores estão nos cargos, aliado à sua idade e experiência profissional e acadêmica na área de turismo e correlatas, pode contribuir para o processo de tomada de decisões.

\subsection{Importância das Informações para o Desempenho das Atividades Profissionais}

Os gestores identificaram variados graus de importância da informação para o desempenho das atividades que realizam. O secretário vê a informação como fundamental dentro de um ambiente macro do mercado turístico. Enfatiza, "eu acho que no mundo de hoje com as alterações que estão acontecendo, a informação é fundamental. No turismo, está havendo uma mudança nos paradigmas. A informação possibilita uma mudança nos paradigmas devido a sua capacidade de tornar o turista bem informado. É possível também que se avaliem cenários futuros".

Para o diretor 1 a importância da informação está associada à realização de planos de ação, enquanto o diretor 2 considera que a informação representa 'tudo' para o desempenho de suas funções. Observa-se que os gestores possuem percepções aceitáveis do significado da informação à medida que manifestam sua aplicabilidade no desempenho das atividades profissionais que realizam. Verifica-se a existência de graus diferenciados de importância da informação, considerando as respostas dadas. O gestor credita à informação um grau de importância estratégica à medida que observa as mudanças no cenário turístico nacional e internacional. $\mathrm{A}$ fala do diretor 1 revela um grau de importância intermediário - gerencial - utilizado para o desempenho diários das atividades. Por sua vez, a declaração do diretor 2 se mostrou duvidosa no sentido da amplitude da palavra 'tudo', revelando uma possível incompreensão do seu significado, profundidade e complexidade.

\subsection{Canais e Fontes de Informação}

Os canais de informação são diferentes para cada um dos gestores, de acordo com a tabela 1. É importante citar que o secretário se utiliza, de modo geral, 
da mídia como o canal de informação, seja ela escrita, falada ou televisionada. O diretor 1 consulta os órgãos públicos de turismo, eventos/feiras e a mídia escrita, nessa ordem de importância. Por sua vez, o diretor 2 consulta o trade turístico, os órgãos públicos de turismo e os turistas/comunidade local. Entre os canais de informação mais comuns aos gestores estão a mídia escrita e os órgãos públicos diversos e de turismo. Este último revela a preocupação em saber o que acontece no ambiente turístico nas suas demais esferas que podem ter relação direta com o órgão municipal que gerenciam.

Traçando um paralelo com os resultados do estudo de Curty (2005) e este trabalho, nota-se uma diferença entre um canal de informação utilizado pela iniciativa privada e a pública, respectivamente. No primeiro, a universidade é aproveitada como importante canal informacional, enquanto que no órgão público esta situação não foi detectada pelos gestores e também pelos funcionários. Destaca-se que no município sede da organização, está localizada uma das maiores universidades do Estado cujo curso superior em Turismo e Hotelaria é classificado pelo Guia do Estudante (2011) como o único cinco estrelas do país.

Tabela 1 - Principais canais de informação dos gestores

\begin{tabular}{l|c|c|c|c|c|c}
\hline \multirow{2}{*}{ Canais de informação } & \multicolumn{2}{|c|}{$\mathbf{1}$} & \multicolumn{2}{|c|}{$\mathbf{2}$} & \multicolumn{2}{c}{3} \\
\cline { 2 - 7 } & $\boldsymbol{F}$ & $\%$ & $\boldsymbol{F}$ & $\%$ & F & $\%$ \\
\hline Associações de turismo e afins & - & - & - & - & - & - \\
Centrais de informações turísticas & - & - & - & - & - & - \\
Consultores & - & - & - & - & - & - \\
Destinações turísticas & - & - & - & - & - & - \\
Órgãos públicos e/ou de turismo & 1 & 33,33 & 1 & 33,33 & - & - \\
Eventos/feiras & - & - & 1 & 33,33 & - & - \\
Fornecedores & - & - & - & - & - & - \\
Outras associações & - & - & - & - & - & - \\
Universidades/IES & - & - & - & - & - & - \\
Trade turístico & 1 & 33,33 & - & - & - & - \\
Turistas / Comunidade local & - & - & - & - & 1 & 33,33 \\
WEB & - & - & - & - & - & - \\
Mídia escrita (jornal) & 1 & 33,33 & - & - & 1 & 33,33 \\
Mídia falada (rádio) & - & - & 1 & 33,33 & - & - \\
Mídia televisionada & - & - & - & - & 1 & 33,33 \\
\hline Total & 3 & 100,0 & 3 & 100,0 & 3 & 100,0 \\
\hline
\end{tabular}

Fonte: Guia do estudante (2011). 
Correlacionando aos canais de informação, as fontes consultadas pelos gestores são ora diferentes ora semelhantes entre si (tabela 2). Para o secretário se resumem em jornais e revistas especializadas. Para o diretor 1 , a fonte mais consultada é o BDD (Banco de Dados) interno da Secretaria, enquanto para o diretor 2 são os relatórios diversos. São fontes comuns aos três gestores, os artigos de jornais e revistas especializadas. Percebe-se que as fontes consultadas pelos gestores são as disponíveis no ambiente interno da organização, on-line ou impressa. A facilidade no acesso permite que os gestores economizem tempo dinamizando suas atividades profissionais. Cândido, Valentim e Contani (2005) avaliam que a correta identificação das fontes para cada ambiente e ator, acarretará em um gerenciamento dinâmico e efetivo da informação.

Tabela 2 - Principais fontes de informação dos gestores

\begin{tabular}{l|c|c|c|c|c|c}
\hline \multirow{2}{*}{ Fontes de informação } & \multicolumn{2}{|c|}{$\mathbf{1}$} & \multicolumn{2}{|c|}{2} & \multicolumn{2}{c}{3} \\
\cline { 2 - 7 } & $\boldsymbol{F}$ & $\%$ & $\boldsymbol{F}$ & $\%$ & F & $\%$ \\
\hline Artigos de jornais, revistas especial. & 1 & 33,33 & 1 & 33,33 & 1 & 33,33 \\
Atas de encontros e reuniões & - & - & - & - & - & - \\
Banco de dados & 1 & 33,33 & - & - & - & - \\
Comunicações internas/ofícios & - & - & - & - & - & - \\
Folders, panfletos e informativos & - & - & - & - & 1 & 33,33 \\
Livros & - & - & - & - & - & - \\
Mapas e guias & - & - & - & - & - & - \\
Manuais & - & - & - & - & - & - \\
Periódicos científicos & - & - & - & - & - & - \\
Publicações governamentais & - & - & - & - & - & - \\
Relatórios diversos & 1 & 33,33 & 1 & 33,33 & - & - \\
Sites da internet & - & - & - & - & - & - \\
Não respondeu & - & - & 1 & 33,33 & 1 & 33,33 \\
\hline Total & 3 & 100,0 & 3 & 100,0 & 3 & 100,0 \\
\hline
\end{tabular}

Fonte: Dados da pesquisa

Nota-se ainda que a relevância das fontes utilizadas pode cooperar para a maximização do conteúdo informacional que os gestores acessam. Por outro lado, a restrição ao acesso de fontes diversificadas pode comprometer a qualidade das informações obtidas gestores. Se observados os resultados da pesquisa de 
Nascimento e Silva (2004) com os desta pesquisa, avalia-se que os BDD são fontes imprescindíveis ao mercado turístico, tanto no âmbito público quanto privado.

Os aspectos considerados determinantes para a escolha dos canais para o secretário permeiam a confiança. Para o diretor 1 a experiência profissional na área e a formação acadêmica permitem avaliar o que tem valor. Para o diretor 2 não há critério de escolha, pois todos são interessantes. Os critérios determinantes para as fontes são os mesmos identificados para os canais de informação. A confiança é o principal aspecto determinante tanto na escolha das fontes quanto dos canais de informação. Correlacionando-o com os resultados das fontes e canais acessados, visualiza-se que os gestores primam pelo seu tradicionalismo, ou seja, se acessam os jornais, os BDD e os relatórios é porque confiam nas informações disponíveis nessas fontes.

\subsection{Repasse de informações para os demais membros da Secretaria}

Os diretores utilizam o procedimento de repassar as informações em primeiro lugar para o próprio setor, em seguida para o secretário. Este por sua vez afirma "Esta área precisa de aperfeiçoamento. Ainda não é possível que todos saibam. O problema é que você entra em uma roda, onde as coisas acontecem tão rápido que no fim não dá tempo para o repasse. Cada área sabe da sua. É preciso melhorar e mudar esse aspecto". Sua declaração evidencia que a gestão da informação não acontece de forma plena no órgão, necessitando de melhorias na estrutura de informática (softwares, hardwares) e na humana, no sentido de qualificar e treinar os funcionários para tal função.

A comunicação das informações pode ser avaliada como sendo de forma horizontal e vertical, sob a perspectiva da hierarquia organizacional. A comunicação das informações, nessa organização, se dá de modo vertical, de gestores para coordenador e funcionários do setor; e de modo horizontal entre gestores e funcionários. Estas formas de comunicação podem ampliar a quantidade de informações no fluxo, desde que bem conduzido. No entanto, verifica-se que a SECTUR ainda enfrenta problemas de comunicação, principalmente inter-setorial.

Quanto ao recebimento das informações, o secretário as recebe de seus diretores através de conversas. Já os diretores recebem informações de diferentes membros da organização, como funcionários em viagens a eventos e feiras e pela 
assessoria de imprensa. É interessante notar que diretor 1 costuma receber informações de funcionários que não pertencem ao seu setor. Por outro lado, o recebimento de informações pelo diretor 2 acaba não acontecendo. A figura 1 demonstra a forma de recebimento destas informações.

Figura 1- Recebimento de informações pelos principais membros da SECTUR

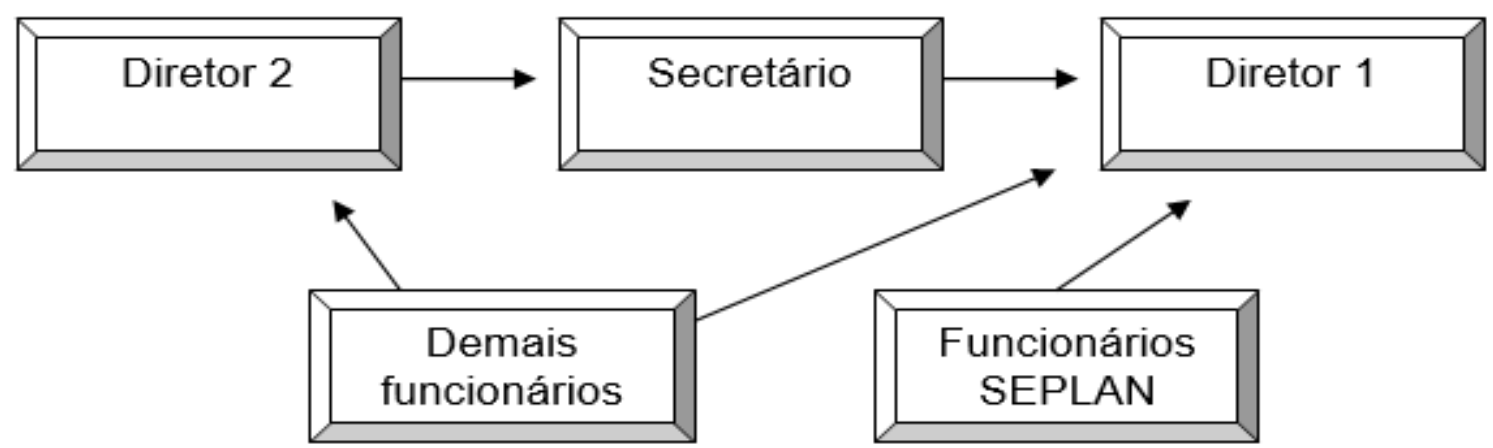

Fonte: Dados da pesquisa

Observa-se que o fluxo de informações segue no sentido vertical das informações, de baixo para cima. Acredita-se que a forma de recebimento seja coerente à medida que o secretário centraliza as informações principalmente vindas dos diretores (em função da hierarquia). Por sua vez, o recebimento de informações pelo diretor 2 necessita ser revista e ampliada, visando ampliar as informações dos demais setores.

\subsection{Barreiras de Acesso à Informação}

No que se refere às barreiras de acesso à informação, o diretor 1 declarou que o material disponível na internet é desatualizado, enquanto que para o diretor 2 é a morosidade da estrutura pública e o excesso de burocracia. As demais barreiras identificadas são: a carência de BDD e a dificuldade de localizar determinada informação.

A avaliação das barreiras de acesso à informação pelos gestores permite duas inferências. A primeira é sua inexistência por parte do secretário. Este resultado por ser comparado com o estudo de Curty (2005) que também obteve semelhante resposta. A ausência de barreiras supõe que o usuário saiba como obter determinada informação, ou que as fontes consultadas são as mesmas. Outra 
inferência é decorrente do canal informacional, os BDD que necessitam ser ampliados e atualizados. Neste sentido, a preocupação da OMT (ORGANIZAÇÃO MUNDIAL DO TURISMO, 2001) em incentivar que governos invistam na criação, disponibilização e manutenção de BDD, é totalmente fundamentada tendo em vista as deficiências encontradas.

As estratégias para obter determinada informação variam conforme o gestor, que vão desde o contato com trade turístico, a busca na internet e a consulta em outro canal de informação. Dois gestores, entre eles o secretário, responderam não ter dificuldades em conseguir as informações que desejam, correlacionando-se com a questão anterior. Para o outro diretor, a estratégia se inicia pela internet (através de sites de busca); caso não esteja disponível entra em contato via telefone com órgãos públicos de turismo como a SANTUR, Ministério do Turismo e demais destinações turísticas. De maneira geral, as estratégias para impetrar determinada informação se mostraram distintas e variadas para cada gestor, ao mesmo tempo em que afirmaram consegui-las facilmente.

A facilidade declarada pelos gestores na obtenção de informações é decorrente da sua experiência profissional, do seu amplo conhecimento do/e perante trade turístico e ainda, pelo nível de exigência requerido de uma informação em termos de qualidade e profundidade do seu conteúdo. Dentre estas, a última característica é a que poderá interferir nas estratégias utilizadas pelos gestores, pois quanto mais alto o grau de exigência, maiores serão os esforços na busca para consegui-las.

Quando questionados se as dificuldades no acesso a determinadas informações interferem nas decisões a serem tomadas, observa-se que o secretário possui noção da importância da informação para o processo decisório. "Se eu não tenho conhecimento fica difícil tomar uma decisão". Por sua vez, o diretor 1 defende que se não tiver determinada informação dificulta a tomada de decisão, mas que se não for possível obtê-la, a decisão acontecerá da mesma maneira. Para o diretor 2, as dificuldades no acesso não alteram o processo de tomada de decisões, revelando um hábito antigo de gerenciamento, baseado essencialmente na intuição e na experiência profissional adquirida.

Genericamente, infere-se que o processo decisório acontece de maneira informal e baseado na intuição e na experiência de seus gestores. Quando se 
utilizam de uma informação, esta é principalmente do tipo oral e informal, ou seja, ela exerce um papel complementar e secundário no processo decisório.

Avaliando as dificuldades no acesso, nos reportamos ao estudo de Angeloni (2003) que comprova as dificuldades no acesso as informações podem ser minimizadas por dois aspectos: a melhoria na comunicação entre os membros da organização e o trabalho em equipe. Estes aspectos podem ser aplicados ao ambiente organizacional da SECTUR, pois permitiriam que as dificuldades fossem minimizadas, e posteriormente, que um maior número de informações fosse utilizado no processo decisório pelos gestores. Por conseguinte, as melhorias no trabalho em equipe contribuiriam para que os mesmos tivessem acesso a um maior volume de informações, melhorando o seu repasse.

Para os gestores da Secretaria não há motivos que os faça desistir de obter determinada informação. O secretário aponta que o celular é uma ferramenta imprescindível para conseguir a informação desejada. $O$ diretor 1 afirma que só desiste se a informação não está disponível.

As respostas convergem no sentido da insistência por parte dos gestores em não desistir de obter uma informação, fato que pode contribuir para a qualidade do fluxo informacional do órgão. Considera-se que a não desistência em se obter uma informação esteja relacionada também com o número relativamente baixo de barreiras enfrentadas, bem como pela experiência dos gestores em saber onde, como e com quem podem consegui-la. Estes fatores, quando empregados, constituem-se em benefícios ao fluxo informacional.

\subsection{Necessidades e Motivações de Informação}

A principal necessidade de informação do secretário e do diretor 1 é tomar uma decisão, revelando inquietude com o processo para a obtenção de melhores resultados organizacionais. Para o diretor 2, a principal necessidade é a de solucionar um problema. Em segundo lugar, as necessidades informacionais surgem no desenvolvimento das atividades rotineiras, e finalmente, atingir novos segmentos e estimar custos. Evidencia-se que a principal necessidade informacional de seus gestores é a tomada de decisões, denotando sua relevância. Observa-se que estes resultados têm respaldo na literatura das áreas de Ciência da Informação $(\mathrm{Cl})$ e Turismo, a exemplo do estudo de Zegarra (2000) e do Ministério do Turismo 
(BRASIL, 2006), apenas para citar dois. Ambos convergem ao pensamento de que os gestores públicos ou privados necessitam de informações oportunas, úteis e de qualidade para o suporte adequado do processo decisório. Se na $\mathrm{Cl}$ este aspecto é amplamente pesquisado, no campo do turismo são recentes os estudos que evidenciam tal importância. Desta forma, surpreende as respostas obtidas de dois dos gestores, comprovando as suas necessidades em relação à utilização de informações para auxiliar a tomada de decisões.

Para os três gestores da organização as necessidades motivam a busca por informações, ressaltando a resposta do diretor 2: "você tem que estar permanentemente motivado a buscar informações. Eu vejo que no futuro o segredo será você aprender a acessar a informação", expondo a preocupação de como acessar a informação.

Em vista dos resultados apontados pela pesquisa, verifica-se que a motivação é fator básico e ao mesmo tempo primordial para que os usuários busquem informações, cooperando, em última instância, para a qualidade das informações no fluxo, desde que saibam acessar fontes confiáveis. A motivação dos gestores na busca e acesso às informações tem um caráter exploratório relevante, relacionado ao processo decisório. Assim, se estiverem motivados poderão desempenhar eficazmente suas atividades.

\subsection{Qualidade da Informação}

Uma informação de qualidade é, para os gestores, aquela que os ajuda no momento da tomada de decisão. Para o diretor 1: "é importante que a informação seja de fácil compreensão e leitura. Para o dia-a-dia é fundamental que as informações sejam básicas. Quando for o caso de uma tomada de decisão, esta pode ser mais rebuscada". Nesse sentido, percebe-se a unanimidade em considerar que a qualidade da informação interfere diretamente nas decisões tomadas. Outro aspecto revelado pelos gestores diz respeito à utilidade da informação, ou em outras palavras, é necessário que ela seja dotada de contextualização prática, podendo ser aplicada no cotidiano.

A qualidade das informações é fator imprescindível para o fluxo informacional de uma organização. No momento atual, em que a quantidade de informações disponível é elevada, saber distinguir uma informação de qualidade de outra é vital 
para o processo decisório. Dantas (2005) chegou a resultados semelhantes, observando que a informação terá mais qualidade quanto mais qualidade tiver o processo de gestão da informação na organização. Destaca-se que a qualidade é subjetiva variando conforme a visão do gestor ou funcionário. Neste sentido, é preciso que a organização busque incessantemente ampliar a comunicação existente entre seus membros, bem como as fontes e o conteúdo informacional acessado. Estas atitudes poderão melhorar a qualidade geral das informações, e conseqüentemente, o seu processo de gerenciamento.

As maneiras de obtenção da qualidade das informações do ambiente externo pelos gestores foram verificadas, visando complementar a análise da variável. Estas maneiras se mostraram diferentes para cada gestor. Para o secretário, a experiência profissional e a bagagem empresarial adquirida proporcionam distinguir uma informação de qualidade de outra. Já o diretor 1 acredita e se baseia nos autores de renome da área, enquanto que o diretor 2 busca o contato pessoal com 0 trade turístico. Estas variadas maneiras interferem positivamente na hora de conseguir uma informação de qualidade do ambiente externo, pois não estão concentradas em um único aspecto da informação, desde que a decisão seja tomada em conjunto.

\subsection{Tipo de Informação Produzida}

As principais informações produzidas pela Secretaria são a home-page, as revistas, os jornais e as visitas a eventos e feiras. É interessante destacar que os gestores deram diferentes respostas para as informações que produzem para o ambiente externo, demonstrando dois possíveis aspectos: (1) variedade de informações colocadas à disposição dos clientes; (2) falta de foco na produção de informações ao público externo.

Apenas para o secretário a home-page é a principal informação a ser disponibilizada ao ambiente externo, embora declare que esta não esteja operando plenamente, necessitando de melhorias e ajustes. O estudo de De Lucca Filho (2005) vem reforçar essa afirmativa. Nele estão presentes as deficiências em termos de foco e produção de materiais informativos de qualidade, cujo conteúdo e forma sejam aceitáveis e cumpram sua função de dotar os clientes (turistas) de informações oportunas, verídicas e úteis. Outra inferência em relação aos materiais 
informativos, refere-se ao cuidado que se deve ter em divulgar apenas informações fidedignas e reais.

O trabalho de Nascimento e Silva (2004) corrobora desta afirmativa, acrescentando que o material de divulgação deve passar por um processo criterioso e seguro das informações que serão disponibilizadas. No caso desta pesquisa, infere-se que a quantidade de tipos de materiais produzidos pelo órgão não representam necessariamente a qualidade deles esperada. No entanto, a preocupação com a inserção - mesmo que gradativa - de uma home-page estruturada e com informações de qualidade, evidencia que ações positivas estão sendo tomadas. É necessário ainda, que o cliente tenha acesso a materiais escritos nos postos de informações, caso contrário uma de suas funções principais estará comprometida. Observa-se que a decisão dos gestores pelos tipos de informações produzidas deve levar em conta não só o público a que se destina, mas que o conteúdo e a qualidade das informações seja colocada em posição de destaque.

Os principais meios de comunicação para divulgação das informações segundo seus gestores são a internet e as revistas. Em segundo lugar, os gestores identificaram os eventos/feiras, os releases e os jornais. Foi ressaltado pelo secretário que a organização gostaria de poder investir mais na televisão como meio de comunicação, pois atinge uma significativa parcela da população, mas que não o fazem devido aos elevados custos. No entanto, este item não foi mencionado na questão relativa ao principal fator que prejudica/impossibilita as informações a serem fornecidas ao mercado.

Outro aspecto mencionado é a relação existente entre as informações produzidas pela Secretaria e os meios de comunicação utilizados pelo órgão para divulgação das informações. Evidencia-se que a organização tem agido de maneira coerente em relação à divulgação nos meios de comunicação.

Porém, as considerações feitas no item anterior em relação ao foco de atuação são válidas para os meios de comunicação utilizados para a divulgação das informações. A escolha dos meios de comunicação mais adequada à SECTUR pode representar ganhos de fatias de mercado incrementando a oferta turística disponível. Assim como no estudo de Nascimento e Silva (2004) o meio de comunicação eletrônico vem ganhando espaço no mercado, evidenciado pelas tecnologias de informação e comunicação, sendo a internet amplamente empregada na divulgação das informações turísticas por organizações públicas e privadas. 
Os gestores foram unânimes em responder que os meios de comunicação suprem as necessidades da secretaria. No entanto, segundo o secretário "esses meios suprem cerca de $80 \%$ das necessidades. O que acontece é que nem sempre é possível investir quanto se quer na mídia". É interessante comparar esta resposta com a que declara que a mídia prejudica o turismo e a organização. É possível que este fato seja resultante de uma questão histórica de que o Sul do País, mais especificamente o Estado de SC, não receba a devida atenção em se tratando de turismo pelos principais veículos de comunicação nacionais.

\subsection{Processo de Disponibilização das Informações ao Ambiente Externo}

Nas declarações dos diretores, percebe-se que há pelo menos três formas de disponibilizar informações ao mercado externo. A primeira delas, pelos Postos de informação turística (PIT's) cujos principais receptores são os turistas e visitantes. Em segundo lugar, para o trade turístico e comunidade em geral, através do SEPLAN. Finalmente, através de releases enviados a imprensa pela assessoria de imprensa. Conforme relato de um dos diretores, este processo acontece sem burocracia, através de solicitação escrita ou até mesmo oral. Para o secretário, esse processo passa por uma fase de ampliação, de forma gradativa, onde estão sendo realizadas ações para maximizar a divulgação de informações turísticas ao mercado, tais como: reformulação e inserção de conteúdos da home-page e divulgação intensiva do calendário de eventos.

Almejava-se que os postos de informações fossem citados também como meio de comunicação não-convencional para a divulgação das informações turísticas do órgão e do município. Considera-se que os postos são indispensáveis na disponibilização de informações, atingem uma parcela significativa e abrangente de clientes (turistas, população, trade). Pensa-se que a organização deve voltar sua atuação para os PIT's desejando se aproximar dos clientes.

Quanto aos fatores que impossibilitam ou prejudicam as informações de serem fornecidas ao mercado, para o secretário, o principal fator é a mídia, que vem interferindo no turismo na cidade com reportagens nem sempre verídicas e dotadas de sensacionalismo. Ressalta-se que é justamente a mídia a única fonte de informação utilizada pelo secretário. Os diretores afirmam que não há fator que prejudique que as informações sejam disponibilizadas ao mercado turístico. 
Considerando os aspectos não citados, salienta-se que ouve certa pretensão por parte de dois gestores que afirmam que não há fator que impossibilita/prejudica o fornecimento de informações ao mercado externo.

De forma geral, os gestores entrevistados tomam a decisão da seguinte forma: "tomo a partir do momento em que eu percebo que é o melhor para a cidade e para a administração. Nós temos o privilégio da liberdade para administrar por parte do prefeito. Outro ponto importante é o meu conhecimento anterior na área [experiência] mais o conhecimento técnico [formação acadêmica]". O diretor 2 tem uma visão clara do assunto em termos do processo na administração pública municipal. "A decisão é dotada de complexidade [...]. A tomada de decisão no órgão público é difícil, pois a estrutura muitas vezes é pesada, burocrata, há que obedecer a uma série de fatores. Você fica dependente de acontecimentos, situações e problemas com custos, diferente da iniciativa privada onde você tem maior liberdade de ação". Para o diretor 1 a decisão é baseada no feeling pessoal e profissional, afirmando que ela ocorre esporadicamente, pois o órgão está funcionando de modo satisfatório.

Verifica-se que as decisões são baseadas na experiência profissional, na formação acadêmica e no feeling dos gestores, apesar de afirmarem que a maior necessidade de informação decorre da tomada de decisão (item 2.5) quando, de fato, não a utilizam para esse fim. Afirma-se que, além da subutilização das informações, a decisão ocorre no topo da hierarquia, neste sentido, as decisões são tomadas sem que haja certeza ou confiança nos resultados futuros. Outro aspecto que merece destaque é que a Secretaria parece não possuir um plano estratégico de atuação, embora venha desempenhando com certo êxito suas atividades.

Denota-se que à medida que os problemas surgem, as decisões são tomadas, dotadas de improviso e obrigatoriedade. As conseqüências quanto à qualidade dos resultados, aliada a falta de utilização de informações podem acarretar em perdas de vantagem competitiva perante as demais destinações turísticas. 


\section{CONSIDERAÇÕES FINAIS}

Concorda-se com Teixeira Filho (2000) no sentido de que a informação representa um aspecto vital para a elaboração de estratégias organizacionais que possibilitam à organização manter-se competitiva e atuante. Paralelamente, Cândido, Valentim e Contani (2005) partilham da idéia de que a tomada de decisões exige que a organização gerencie estrategicamente o fluxo informacional.

A complexidade da gestão informacional e também do processo decisório no setor turístico brasileiro ainda não se desenvolveu ao ponto de ser gerenciada eficazmente. Por conseguinte, os municípios turísticos ainda não conseguem fazê-lo com êxito, seja por falta de reconhecimento de sua importância para a economia, de investimentos públicos e privados, ou ainda pela incipiência de profissionais gabaritados na área. Entende-se que o município alvo deste estudo é um bom exemplo em termos de gestão do turismo público, mas ainda não vem utilizando a gestão da informação para o desenvolvimento de suas atividades e também como recurso estratégico para a obtenção de vantagem competitiva.

\section{REFERÊNCIAS}

ANGELONI, Maria Terezinha. Elementos intervenientes na tomada de decisão. Ciência da Informação, Brasília, v. 32, n. 1, p. 17-22, jan./abr. 2003.

BRASIL. Ministério do Turismo. Turismo no Brasil: 2007 - 2010. Brasília, 2006.

CÂNDIDO, Carlos Aparecido; VALENTIM, Marta Lígia Pomim; CONTANI, Miguel Luiz. Gestão estratégica da informação: semiótica aplicada ao processo de tomada de decisão. Data Grama Zero, Rio de Janeiro, v. 6, n. 3, jun. 2005. Disponível em: <http://www.dgz.org.br/jun05/F_I_art.htm>. Acesso em: 22 jul. 2010.

CURTY, Renata Gonçalves. O fluxo da informação tecnológica no projeto de produtos em indústrias de alimentos. 2005. 249 f. Dissertação (Mestrado em Ciência da Informação) - Universidade Federal de Santa Catarina, Florianópolis, 2005.

DANTAS, Maria Carolina Barbosa. A gestão da informação na tomada de decisão em uma instituição financeira brasileira orientada para o cliente. 2005. $137 \mathrm{f}$. Dissertação (Mestrado em Ciência da Informação) - Universidade de Brasília, Brasília, 2005. 
DE LUCCA FILHO, Vinicius. Estudo do fluxo de informações em centros de informações turísticas de Santa Catarina: Programa Portais do Lazer. 2005. $135 \mathrm{f}$. Dissertação (Mestrado em Ciência da Informação) - Universidade Federal de Santa Catarina, Florianópolis, 2005.

GUIA DO ESTUDANTE. Prêmio cursos superiores no Brasil. 2011. Disponível em: <http://guiadoestudante.abril.com.br>. Acesso em: 10 dez. 2012.

NASCIMENTO, Maria de Jesus; SILVA, Paula Sanhudo. Informação: insumo básico para o desenvolvimento do setor de turismo em Santa Catarina. Perspectiva em Ciência da Informação, Belo Horizonte, v.9, n.1, p.48-69, jan./jun.2004. Disponível em: <http://www.eci.ufmg.br/pcionline/viewarticle.php?id=58>. Acesso em: 10 abr. 2012.

ORGANIZAÇÃO MUNDIAL DO TURISMO. Introdução ao turismo. São Paulo: Roca, 2001.

TEIXEIRA FILHO, Jayme. Gerenciando conhecimento. Rio de Janeiro: SENAC, 2000.

ZEGARRA, Sofía Lilianne Villagarcía. Diretrizes para a elaboração de um modelo de gestão de fluxos de informações como suporte à logística em empresas construtoras de edifícios. 2000. 214 f. Dissertação (Mestrado em Engenharia de Construção Civil) - Escola Politécnica da Universidade de São Paulo, Universidade de São Paulo, São Paulo, 2000.

Title

The flow of information from the perspective of public managers in tourism

\begin{abstract}
Introduction: Information plays an important and indispensable role in all public and private organizations, requiring effective management and joint efforts of its members. Information management requires the establishment of procedures, steps or systematized and structured flows, associated with people responsible for its conduct, so they can obtain the desired results. Tourism is a socioeconomic activity that has attracted the attention of governments, businesses, communities and scholars, particularly regarding its organization and management.

Objective: The aim of this study was to analyze the information flow subsidizing the process of decision making in a municipal agency of tourism.

Methodology: The research is characterized as quantitative and qualitative, case study and technique of data collection was semi-structured interview, applied with three managers responsible for the Secretariat through semi-structured interviews with managers.

Results: The results confirmed that although the flow has some structure, is not endowed with formal systematization, occurring deficiencies in their steps.
\end{abstract}


Conclusion: Research on the information flow reflects a path to the consolidation of tourism and the recognition of its importance as a socioeconomic phenomenon and cultural. In view of these results, it appears that the centralization, coupled with the underutilization of information flow affects the quality of decision-making process.

Keywords: Flow of information. Decision making. Tourism.

\section{Título}

El flujo de la información en la perspectiva de los gestores públicos en el sector turístico

\section{Resumen}

Introducción: La información juega un importante e indispensable en todas las organizaciones públicas y privadas, que requieren una gestión eficaz y los esfuerzos conjuntos de sus miembros. Gestión de la información requiere el establecimiento de procedimientos, pasos o flujos sistematizados y estructurados asociados a las personas responsables de su conducta, a fin de obtener los resultados deseados. El turismo es una actividad socioeconómica que ha atraído la atención de los gobiernos, las empresas, las comunidades y académicos, especialmente en cuanto a su organización y gestión.

Objetivo: El objetivo de este estudio fue analizar el flujo de información que apoye la toma de decisiones en la agencia municipal de turismo decisión.

Metodología: La investigación se caracteriza por ser, caso de estudio cuantitativo y cualitativo y la técnica de recolección de datos fue la entrevista semi-estructurada, aplicada a tres gestores responsables de la Secretaría.

Resultados: Los resultados confirmaron que, aunque la corriente tiene cualquier estructura, que está provista de defectos formales sistemáticos que se producen en sus pasos.

Conclusión: La investigación sobre el flujo de información refleja un camino hacia la consolidación del turismo y el reconocimiento de su importancia como fenómeno socioeconómico y cultural.Em vista de los resultados obtenidos, parece que la centralización asociado con la subutilización de flujo de información compromete la calidad el proceso de toma de decisiones.

Palabras clave: Flujo de información. Toma de decisiones. Turismo.

Recebido em: 10.08.2013

Aceito em: 16.12.2014 